\title{
BENTUK DAN FUNGSI LAGU TAWAR SEDENGE PADA MASYARAKAT GAYO DI KABUPATEN ACEH TENGAH
}

\author{
Muhammad Fiqri Rizqullah', Panji Suroso ${ }^{2}$ \\ Program Studi Pendidikan Musik, Fakultas Bahasa dan Seni \\ Universitas Negeri Medan Jl. Willem Iskandar Psr V Medan \\ Sumatera Utara-Indonesia \\ Email:1fiqrizqllh@gmail.com.
}

\begin{abstract}
Abstrak
Tujuan penelitan ini adalah untuk mengetahui bentuk dan fungsi dari lagu Tawar Sedenge yang ada pada masyarakat Gayo Kabupaten Aceh Tengah. Penelitian ini berdasar kepada landasan teoretis yang menjelaskan tentang konsep eksistensi, dan fungsi musik, yang kemudian dipaparkan, dan dijelaskan secara sistematis untuk memperdalam atau menginterpretasikan data secara spesifik dalam rangka menjawab keseluruhan pertanyaan penelitian. Metode penelitian ini menggunakan metode deskriptif kualitatif yaitu dengan mengumpulkan dan menyusun data lalu dipaparkan dan diinterpretasikan. Hasil penelitian menunjukan bahwa; 1) Bentuk lagu Tawar Sedenge merupakan lagu satu bagian dengan bentuk AB. 2) Lagu Tawar Sedenge sebagai fungsi yang terbagi atas sepuluh fungsi yang dikemukakan oleh Alan P. Merriam diantaranya adalah sebagai ekspresi emosional, kenikmatan estetis, hiburan, komunikasi, representasi simbolis, respon fisik, menguatkan konformitas terhadap norma sosial, validasi terhadap institusi sosial dan ritual keagamaan, kontribusi terhadap kontinyuitas dan stabilitas budaya, dan kontribusi terhadap integrasi masyarakat.

Kata Kunci : Tawar Sedenge, Bentuk, Fungsi musik.
\end{abstract}

\begin{abstract}
The purpose of this research is to determine the form and function of the song Tawar Sedenge in the Gayo community of Central Aceh Regency. This research is based on a theoretical basis that explains the concept of form and the function of music, which is then described, and systematically to deepen or interpret the data specifically in order to answer the entire research question. The results showed that; 1) Tawar Sedenge is a one-part song with an AB form. 2) Song Tawar Sedenge as a function divided into ten functions suggested by Alan P. Merriam, including emotional expression, aesthetic pleasure, entertainment, communication, symbolic representation, physical response, strengthening conformity to social norms, validation of social and ritual abuse. Contribution to contribution to the continuity and stability of culture, and contribution to community integration.
\end{abstract}

Keywords: Tawar Sedenge, Form, Music Function. 


\section{PENDAHULUAN}

Masyarakat Gayo adalah salah satu suku bangsa di antara sekitar 300 suku bangsa yang ada di Indonesia. Masyarakat gayo mengenal beberapa alat musik dengan sistem pemakaian yang berbeda-beda, misalnya teganing, canang, bensi, rebana, atau gegedem, genggong, gamang, serune, dan lain-lain. Namun suatu unsur kesenian yang paling menonjol dalam masyarakat adalah seni sastra. Seni sastra ini terwujud dalam beberapa bentuk, seperti kekkitiken, kekeberen, guru didong, didong, sa'er, dan lain-lain.

Masyarakat gayo juga memiliki lagu wajib yang tidak dimiliki daerah-daerah lain salah satunya adalah lagu Tawar Sedenge lagu ini menonjolkan aktivitas dan identitas daerah. Lagu Tawar Sedenge merupakan sebuah lagu yang menggambarkan kekayaan alam tanoh gayo yang terkenal dengan hartanya yang melimpah, dengan pohon pinus yang hijau, kopi, dan tembakau. Disamping itu lagu Tawar Sedenge berisi tentang nilainilai yang mencerminkan dan karakter masyarakat gayo itu sendiri, yang berfungsi sebagai penyemangat dalam melestarikan kakayaan alam di dataran tinggi Gayo.

Pada tahun 1957, Moese menciptakan lagu Tawar Sedenge. Tawar Sedenge merupakan salah satu maha karyanya. Di usia yang masih muda, 17 tahun, moese sudah menciptakan karya monumental bagi masyarakat gayo. Meski lagu ini diciptakan berpuluh-puluh tahun lalu, lagu ini senantiasa melekat dalam hati, jiwa, raga, dan pendengaran suku Gayo. Seperti judulnya "Tawar Sedenge", yang mana kata Tawar dalam bahasa gayo diartikan tawar atau penyejuk. Sementara, sedenge berarti masa lalu atau bisa juga dunia. Lagu ini mengandung pesan agar orang Gayo bersatupadu dalam membangun Tanoh Gayo. Dengan kata lain, ada "nasionalisme lokal" di dalamnya

\section{Musik atau Lagu}

Musik yaitu suatu rangkaian suara atau bunyi yang dihasilkan dari instrumen (alat musik) yang dimainkan secara harmonis oleh seorang atau sekelompok pemusik (orang yang memainkan alat musik). Lagu yaitu rangkaian nada melodi yang disertai syair dan dibawakan oleh seorang atau sekelompok penyanyi. Indrawan (2016: 2), menyatakan bahwa musik merupakan suatu karya seni yang berbentuk lagu atau komposisi yang mengungkapkan perasaan dan pikiran penciptanya melalui unsur-unsur musik seperti irama, melodi, harmoni, bentuk, dan struktur lagu, serta ekspresi (dinamika) menjadi satu kesatuan yang utuh. Prier dalam Indrawan (2016: 2), menyatakan bentuk musik dapat dilihat secara praktis sebagai 'wadah' yang 'diisi' oleh seorang komponis dan diolah sedemikian sehinga menjadi musik yang hidup.

\section{Bentuk Musik}

Bentuk musik adalah hasil dari sebuah rancangan secara keseluruhan yang umumnya tersusun dari potongan-potongan ide musikal yang teratur dan simetris, seperti yang telah dikatakan oleh Prier (2001:5) "bentuk musik sebagai suatu keseluruhan yang umumnya tersusun dari potongan-potongan yang teratur dan simetris". Bentuk musik dimaksudkan sebagai rupa indah yang menimbulkan kenikmatan artistik melalui serapan penglihatan dan pendengaran. Sebagaimana dalam karya sastra bahasa, musik juga memiliki memiliki frase, kalimat, anak kalimat, dan sebagainya. Menurut jumlah kalimat, maka bentuk lagu dibedakan ke dalam tiga jenis (Suroso dkk, 2019: 27) yaitu: 
a. Bentuk lagu satu bagian dengan satu kalimat saja

b. Bentuk lagu dua bagian dengan dua kalimat yang berlainan

c. Bentuk lagu tiga bagian dengan tiga kalimat yang berlainan.

Menentukan bentuk lagu kita harus mengetahui pergerakan frase dan motif agar secara pasti dapat melihat bentuk dari frase dan motif dalam lagu itu sendiri. Frase dalam bentuk musik merupakan bagaian penting yang harus diperhatikan dalam sebuah bentuk lagu atau musik. Frase adalah kumpulan beberapa motif yang memuat sebuah pernyataan. Sebuah frase biasannya tersusun dari empat birama, dimainkan dalam satu nafas tanpa berhenti, dan ditandai dengan kehadiran kadens diujungnya (Suroso, dkk 2019: 24).

Frase itu sendiri terbagi atas dua yaitu pertanyaan dan jawaban. Seperti yang dikemukakan oleh Suroso, dkk, (2019: 24) menyatakan bahawa frase terdiri dari dua jenis yaitu frase pertanyaan (antecendent phrace) dan frase jawaban (consequent phrace) dan gabungan dari ke dua jenis ini disebut dengan kalimat. Motif merupakan bentuk terkecil dari sebuat bentuk lagu. Seperti yang dikemukakan oleh Suroso, dkk, (2019: 16) menyatakan bahwa motif adalah potongan kecil sebuah melodi memuat gagasan/ide sebagai identitas dari sebuah komposisi musik. Sebuah motif biasanya terdiri sekurang kurangnya dari dua nada dan paling banyak dua birama.

\section{Teori Fungsi}

A.R. Radcliffe - Brown mengatakan fungsi adalah kontribusi yang dibuat oleh suatu aktivitas tertentu terhadap aktivitas total yang ia merupakan bagiannya. Fungsi dari suatu kebiasaan sosial tertentu adalah kontribusi yang ia buat terhadap kehidupan sosial secara total sebagai pefungsian dari sistem sosial secara total. Pandangan ini mengisyaratkan bahwa sebuah sistem sosial mempunyai satu jenis tertentu tentang kesatuan (unity), yang dapat kita sebut sebagai suatu kesatuan fungsional. Kita bisa mendefenisikannya sebagai suatu kondisi di mana semua bagian dari sistem bekerja bersama dengan suatu tingkat harmoni yang cukup atau konsistensi internal, yaitu tanpa menghasilkan konflik yang permanen yang tidak dapat dipecahkan atau diatur (Merriam dalam Putra Afriadi, 2017:2). Pernyatan tersebut memberitahukan kepada kita bahwa fungsi kesenian daerah memiliki kesepakatan dalam hal ini tentang konsistensi fungsi tanpa menimbulkan konflik yang permanen.

Beberapa masalah fungsi terangkum kedalam sepuluh konsep fungsi menurut Alan P.Merriam yaitu :

a. Fungsi ekspresi emosional

b. Fungsi tentang kenikmatan estetis (aesthetic enjoyment)

c. Fungsi Hiburan

d. Fungsi Komunikasi

e. Fungsi Representasi Simbolis

f. Fungsi respon fisik

g. Fungsi menguatkan konformitas terhadap norma-norma sosial

h. Fungsi validasi tentang institusi-institusi sosial dan ritual-ritual keagamaan

i. Fungsi tentang kontribusi terhadap kontinyuitas dan stabilitas budaya

j. Fungsi kontribusi terhadap integrasi masyarakat 


\section{METODE PENELITIAN}

Pada penelitian ini menggunakan metode penelitian kualitatif dengan pendekatan deskriptif. Jenis penelitian kualitatif adalah prosedur penelitian yang menghasilkan data deskriptif berupa kata-kata tertulis atau lisan dari orang-orang dan perilaku yang dapat diamati (Rohidi, 2014 : 68). Penelitian ini menggunakan pendekatan deskriptif karena data yang dikumpulkan berupa kata-kata, gambar, dan bukan angka-angka (Rohidi, 2014 : 69). Dalam penelitian kualitatif deskriptif, data yang diperoleh tidak dapat dituangkan dalam bentuk bilangan atau angka statistik, peneliti memaparkan gambaran mengenai hasil yang diteliti dalam bentuk naratif untuk mendeskripsikan atau menggambarkan fenomena-fenomena yang ada di objek penelitian.

\section{HASIL DAN PEMBAHASAN}

Analisis Bentuk lagu Tawar Sedenge

Berdasarkan hasil observasi serta pengumpulan data yang dilakukan oleh penulis maka bentuk Lagu Tawar:

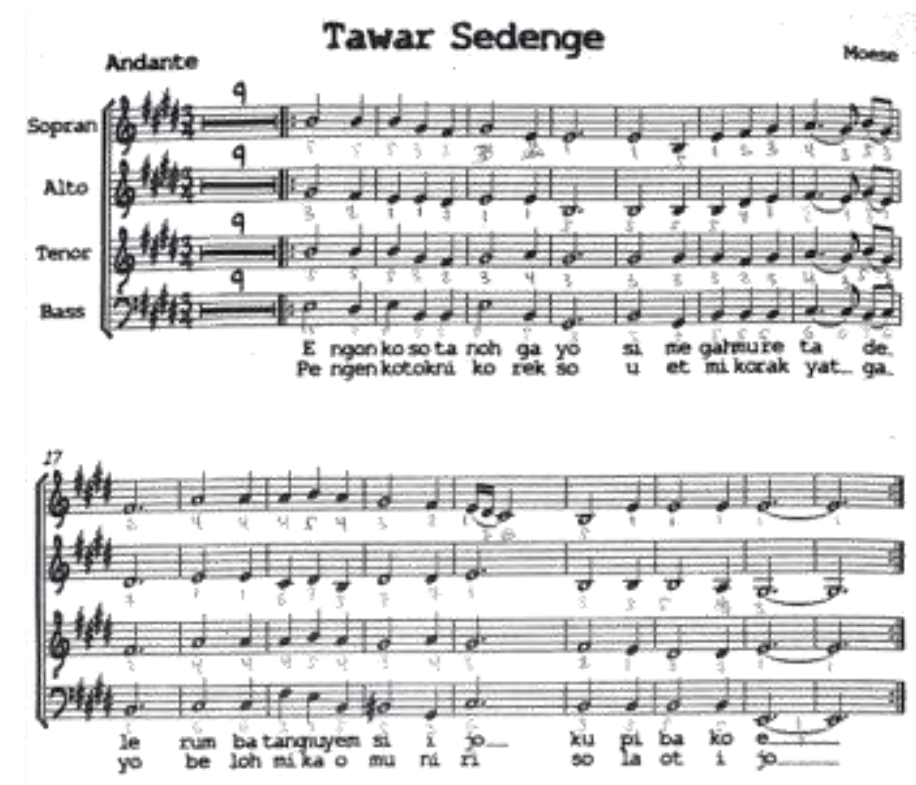




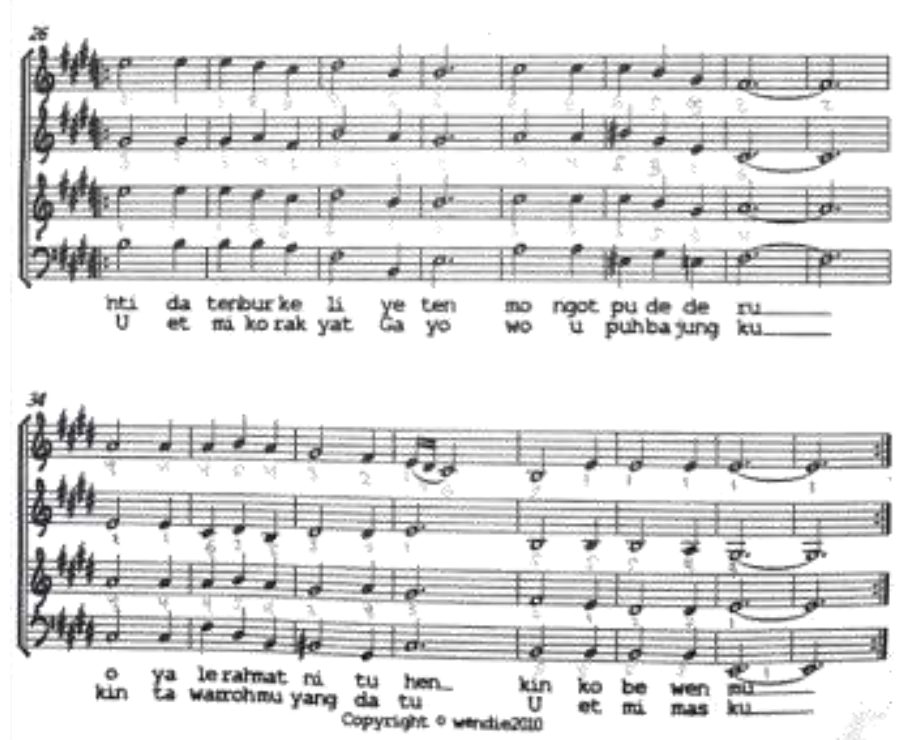

Gambar 1. Partitur Tawar Sedenge full score

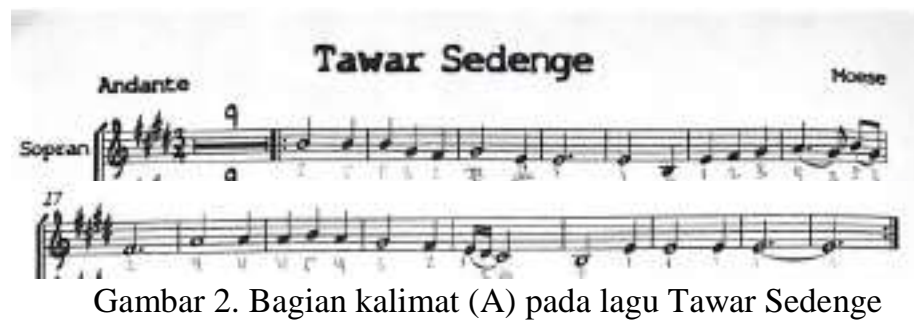

Dapat dilihat pada gambar di atas bahwa dari birama 1 sampai dengan birama 16 (terhitung mulai dari vokal) merupakan bagian pertama pada lagu Tawar Sedenge. Lagu ini dinyanyikan dengan nada dasar E=Do, lagu ini terbilang unik untuk lagu-lagu Himne pada umumnya, namun tidak menghilangkan nuansa hikmat yang ada pada lagu tersebut. Lagu Tawar Sedenge tetap nyaman untuk dinyanyikan oleh semua kalangan masyarakat.

Lagu Tawar Sedenge dibentuk oleh frase-frase yang tersusun dengan indah membentuk satu bagian utuh. Pada bagian pertama pada lagu ini terdapat dua frase yakni frase tanya dan frase jawab, yang membentuk menjadi bagian pertama. Frase tanya dapat dilihat pada birama 1 sampai dengan birama 8 , yang berarti nada pertama dimulai dengan nada $\mathrm{B}=$ sol dan di akhiri nada Fis=re.

Berikut adalah frase tanya pada kalimat A pada lagu Tawar Sedenge.

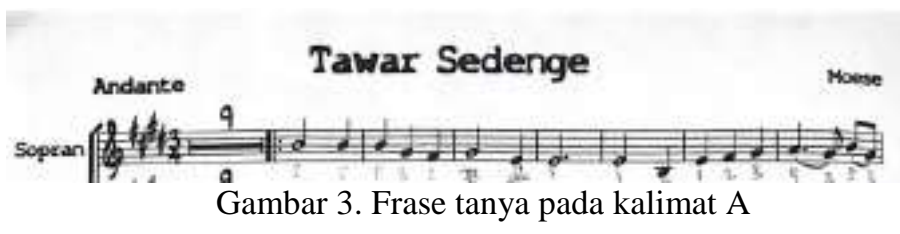


Kemudian, pada frase jawab pada bagian pertama dimulai dari birama 9 sampai dengan birama 16. Pada frase jawab ini nada dimulai dari nada $\mathrm{A}=\mathrm{Fa}$ dan diakhiri nada $\mathrm{E}=$ Do. Pergerakan kadens pada lagu ini membentuk kadens otentik sempurna, yang artinya adalah nada berhenti pada nada awal yaitu $E=$ Do. Berikut adalah frase jawab pada kalimat A pada lagu Tawar Sedenge.

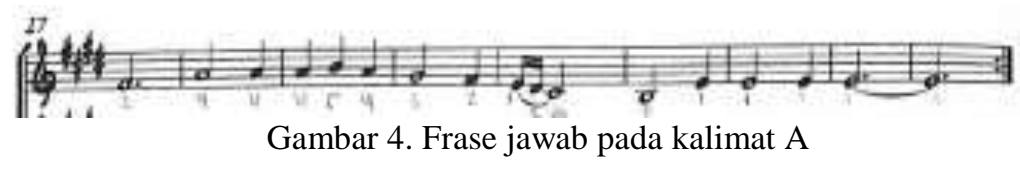

Sedangkan untuk motifnya dapat dilihat pada gambar dibawah ini yang terbagi atas motif pada frase tanya dan motif pada frase jawab:

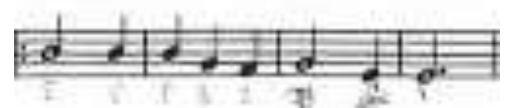

Gambar 5. Motif pertama (frase tanya) pada kalimat A

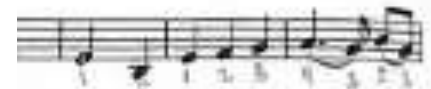

Gambar 6. Motif kedua (frase tanya) pada kalimat A

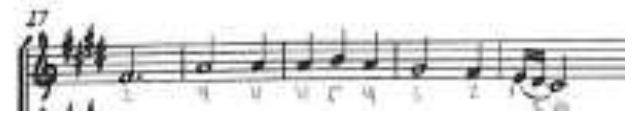

Gambar 7. Motif pertama (frase jawab) pada kalimat A

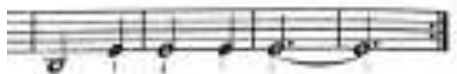

Gambar 7. Motif kedua (frase jawab) pada kalimat A

Selanjutnya pembahasan kalimat B pada lagu Tawar Sedenge adalah sebagai berikut:

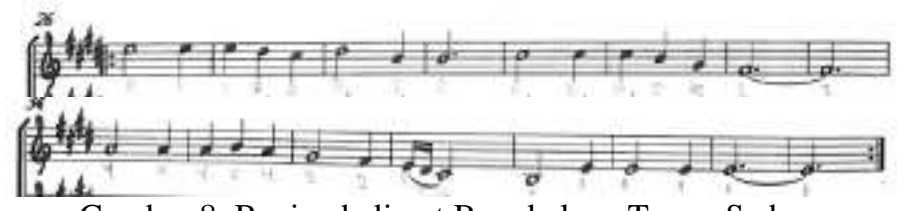

Gambar 8. Bagian kalimat B pada lagu Tawar Sedenge

Bagian kalimat kedua pada lagu ini terdapat dua frase yakni frase tanya dan frase jawab, yang membentuk menjadi bagian kedua seperti pada bagian pertama. Frase tanya dapat dilihat pada birama 17 sampai dengan birama 24, yang berarti nada pertama dimulai dengan nada $\mathrm{E}=$ do dan di akhiri nada Fis=re. Berikut adalah frase tanya pada kalimat $\mathrm{B}$ pada lagu Tawar Sedenge.

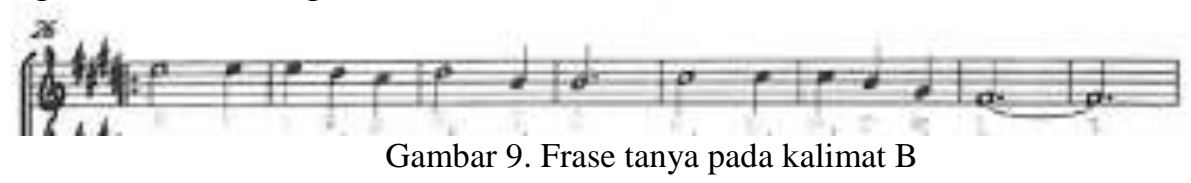


Kemudian, pada frase jawab pada bagian pertama dimulai dari birama 24 sampai dengan birama 32. Pada frase jawab nada dimulai sama seperti frase jawab pada bagian pertama yakni dimulai dari nada $\mathrm{A}=\mathrm{Fa}$ dan diakhiri nada $\mathrm{E}=\mathrm{Do}$. Pergerakan kadens pada bagaian ini pun sama dengan bagian pertama yang membentuk kadens otentik sempurna, yang artinya adalah nada berhenti pada nada awal yaitu $\mathrm{E}=$ Do. Berikut adalah frase jawab pada kalimat B pada lagu Tawar Sedenge.

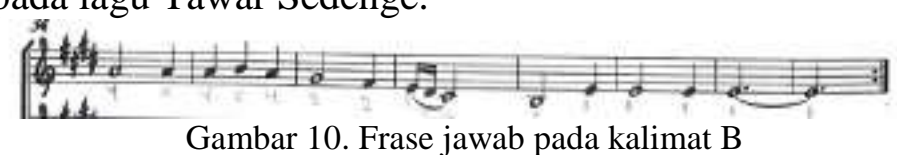

Sedangkan untuk motif dapat dilihat pada gambar dibawah ini, sama halnya dengan pembahasan sebelumnya bahwa terbagi atas motif pada frase tanya dan motif pada frase jawab:

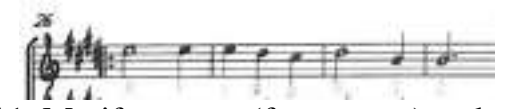

Gambar 11. Motif pertama (frase tanya) pada kalimat B

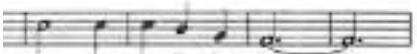

Gambar 12. Motif kedua (frase tanya) pada kalimat B

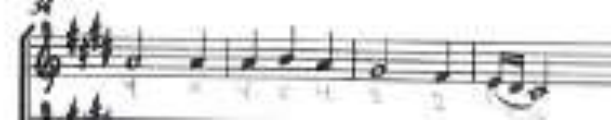

Gambar 13.. Motif pertama (frase jawab) pada kalimat B

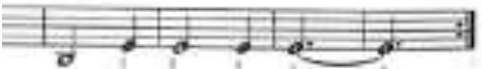

Gambar 14. Motif kedua (frase jawab) pada kalimat B

Berdasarkan pembahasan diatas maka dapat disimpulkan bahwa lagu Tawar Sedenge merupakan lagu satu bagian yaitu dengan kalimat $A B$, dimana lagu tersebut dimulai dengan nada $\mathrm{E}=$ Do yang kemudian diakhiri dengan pergerakan kadens otententik sempurna.

\section{Fungsi Musik Pada Lagu Tawar Sedenge}

\section{Lagu Tawar Sedenge Sebagai Ekspresi Emosional}

Tawar Sedenge sebagai bentuk kebudayaan masyarakat Gayo merupakan luapan ekspresi emosional yang dialami oleh masyarakat Gayo. Menunjukan bentuk dari pola pikir tentang kebudayaan daerah, kemudian hasil pemikiran tersebut diekspresikan ke dalam bentuk kesenian yang sampai saat ini terus bertahan dan menjadi spirit untuk masyarakat Gayo.

\section{Lagu Tawar Sedenge Sebagai Kenikmatan Estetis (aesthetic enjoyment)}

Pemahaman estetik tentang Tawar Sedenge berdasarkan dari masyarakat daerah Gayo itu sendiri, maksudnya adalah apabila ada masyarakat lain yang mendengar lagu Tawar Sedenge maka pemahaman pertama kali yang mereka pikirkan adalah lagu tersebut 
merupakan perwujudan dari budaya masyarakat Gayo itu sendiri, baik dari moral, sosial, dan adat istiadat.

\section{Lagu Tawar Sedenge Sebagai Hiburan}

Sudah tidak diragukan lagi bahwa lagu Tawar Sedenge menjadi sarana hiburan bagi masyarakat Gayo. Hal ini ditunjukan dari lagu Tawar Sedenge yang kerap ditampilkan pada acara-acara kebesaran daerah Aceh Tengah, seperti acara tahunan daerah, lagu Tawar Sedenge selalu dikumandangkan seolah itu menjadi hiburan pembuka bagi penonton atau masyarakat yang berhadir pada acara tersebut. Dalam fungsinya sebagai hiburan yang memiliki nilai adalah lagu Tawar Sedenge yang di dalamnya mengandung pesan adat istiadat daerah.

\section{Lagu Tawar Sedenge Sebagai Komunikasi}

Sebagai fungsi komunikasi, dari semua fungsi musik, lagu Tawar Sedenge sangat sulit untuk dipahami dan dimengerti, hal ini ditunjukan pada isi lirik yang memakai pantun atau prosa tua dalam adat istiadat masyarakat Gayo, hal ini dikarenakan lagu Tawar Sedenge ditujukan untuk masyarakat Gayo khususnya yang berada diperantauan.

\section{Lagu Tawar Sedenge Sebagai Representasi Simbolis}

Lagu Tawar Sedenge dari awalnya merupakan representasi simbolis dari masyarakat Gayo dan adat istiadatnya. Menjadi ungkapan dari ide-ide dan moral yang ada dalam masyarakat Gayo, terus bertahan sampai sekarang. Memang tidak semua bentuk seni merupakan representasi simbolis, namun untuk Tawar Sedenge, hal ini jelas merupakan representasi simbolis dari seluruh aspek dan ruang lingkup kebudayaannya.

\section{Lagu Tawar Sedenge Sebagai Respon Fisik}

Lagu Tawar Sedenge merupakan bentuk kreatifitas yang dimuat menjadi lagu daerah yang memiliki pengaruh terhadap manusia atau masyarakat berupa respon fisik, terlepas itu respon negatif atau positif. Bentuk respon tidak terlalu terlihat, dikarenakan rasa dari sebuah lagu hanya menyentuh ranah kejiwaan bagi yang mendengar dan menghayatinya. Kesenian daerah memiliki pengaruh terhadap manusia atau masyarakat berupa respon fisik, terlepas itu respon negartif atau positif.

\section{Lagu Tawar Sedenge Sebagai Penguatan Konformitas Terhadap Norma-Norma Sosial}

Lagu Tawar Sedenge menjadi penguat konformitas terhadap norma-norma sosial yang ada dikalangan masyarakat Gayo. Pada awal pembahasan telah dikatakan bahwa lagu Tawar Sedenge merupakan ekspresi budaya yang disalurkan melalui lagu yang berisikan nilai-nilai budaya dan adat istiadat masyarakat Gayo.

Sepertinya hal ini memang sudah sangat jelas dapat kita cermati pada lirik yang ada pada lagu Tawar Sedenge. Walaupun peneliti tidak meneliti makna yang terkandung di dalamnya, namun dapat dipastikan bahwa norma-norma sosial yang terkandung di dalam lagu ini sudah sangat terlihat. 


\section{Lagu Tawar Sedenge Sebagai Validasi Tentang Institusi-Institusi Sosial dan Ritual- Ritual Keagamaan}

Sebagai lagu yang menjadi ciri khas daerah, lagu Tawar Sedenge memvalidasi faktor keagaamaan masyarakat Gayo. Hal ini ditunjukan dari lirik lagu Tawar Sedenge terdapat puji-pujian terhadap Tuhan Yang Maha Esa, mayoritas mayarakat Gayo adalah beragama Islam. Pujian terhadap berkah tuhan yang terlihat melalui sumber daya yang menawan di daerah Aceh Tengah. Bentuk seni dimasyarakat itu menunjukan identitas dari institusi sosial dan ritual keagamaan yang ada di daerah tersebut, yang nantinya menjadi ciri khas kesenian daerah.

\section{Lagu Tawar Sedenge Sebagai Kontribusi Terhadap Kontinuitas dan Stabilitas Budaya}

kontribusi semua fungsi seni akan menjadikan seni itu sendiri sebagai stabilitas budaya yang berkelanjutan. Dalam hal ini, lagu Tawar Sedenge menjadi kontribusi yang paling besar dalam kontinuitas dan stabilitas budaya, dikarenakan lagu Tawar Sedenge merupakan identits budaya masyarakat Gayo. Musik memungkinkan ekspresi emosional, memberikan kenikmatan estetis, menghibur, mengkomunikasikan, memunculkan respon fisik, menegakkan konfornitas terhadap norma-norma sosial, dan memvalidasi institusiinstitusi sosial dan ritual-ritual keagamaan, adalah jelas bahwa ia memberikan kontribusi tidak lebih dan tidak kurang dari sembarang aspek kebudayaan yang lain.

\section{Lagu Tawar Sedenge Sebagai Kontribusi Terhadap Integrasi Masyarakat}

Lagu Tawar Sedenge berfungsi sebagai integrasi masyarakat. Lagu Tawar Sedenge tidak semua kalangan mengenal lagi ini, apalagi di masa yang sudah serba modern ini pasti setidaknya ada satu atau dua orang yang tidak ingat atau bahkan tidak peduli akan lagu Tawar Sedenge. Namun yang pasti bagi mereka yang telah mengetahui dan mengenal lagu ini khususnya bagi masyarakat Gayo itu sendiri, walaupun tidak dinyanyikan pada saat acara resmi kedaerahan, tapi mereka pasti dapat mengingat pesan yang disampainkan oleh lagu tersebut yang membuat mereka berkumpul satu sama lain dan mengingat kesatuan mereka kembali. Berdasarkan hasil wawancara dari pengarang lagu Tawar Sedenge mengatakan bahwa walaupun lagu ini tidak dinyanyikan pada setiap acara resmi, namun bagi masyarakat Gayo yang ingat akan lagu ini akan kembali mengingat kebersamaan dan kesatuan yang telah mereka bangun selama hidup menjadi masyarakat Aceh Tengah.

\section{SIMPULAN}

Berdasarkan penelitian lagu Tawar Sedenge pada masyarakat Gayo di kabupaten Aceh Tengah berdasarkan bentuk dan fungsi musik, maka dapat disimpulkan sebagai berikut:

1. Bentuk lagu Tawar Sedenge dibuat secara sederhana dengan bentuk lagu satu bagian dimana memiliki satu kalimat tanya (A) dan satu kalimat jawab (B), arinya adalah lagu Tawar Sedenge merupakan lagu satu bagian dengan bentuk AB. lagu Tawar Sedenge dimulai dengan nada dasar E=Do yang kemudian diakhiri dengan 
pergerakan kadens otententik sempurna. Dengan rincian ada empat frase dan delapan motif pada setiap kalimat dari lagu Tawar Sedenge.

2. Fungsi Lagu Tawar Sedenge, yaitu :

a. Fungsi Lagu Tawar Sedenge sebagai Ekspresi Emosional

b. Fungsi Lagu Tawar Sedenge sebagai Kenikmatan Estetis

c. Fungsi Lagu Tawar Sedenge sebagai Hiburan

d. Fungsi Lagu Tawar Sedenge sebagai Komunikasi

e. Fungsi Lagu Tawar Sedenge sebagai Representasi Simbolis

f. Fungsi Lagu Tawar Sedenge sebagai Respon Fisik

g. Fungsi Lagu Tawar Sedenge sebagai Menguatkan Konformitas Terhadap Norma Sosial

h. Fungsi Lagu Tawar Sedenge sebagai Validasi terhadap Institusi Sosial dan Ritual Keagamaan

i. Fungsi Lagu Tawar Sedenge sebagai Kontribusi terhadap Kontinyuitas dan Stabilitas Budaya

j. Fungsi Lagu Tawar Sedenge sebagai Kontribusi terhadap Integritas Masyarakat

\section{DAFTAR PUSTAKA}

Afriadi, Putra. (2017). "Fungsi dan Multikulturalisme dalam seni didong pada masyarakat gayo kabupaten aceh Tengah". Jurnal: IMAJI. Universitas Negeri Yogyakarta.

Alfianika, Ninit. 2016. Buku Ajar Metodologi Penelitian Pengajaran Bahasa Indonesia. Yogyakarta: Deepublish.

Algayoni, Yusradi Usman. 2015. “Pelestarian Bahasa Gayo”. Jurnal: Serambi Indonesia 2015.

Arikunto, Suharsimi, 1993. Prosedur Penelitian: Suatu Pendekatan Praktis. Jakarta: PT.Rineka Cipta.

Edmund Prier Sj, Karl. 1996. Ilmu Bentuk Musik. Yogyakarta : Pusat Musik Liturgi.

Fatkhurrohman, Ali. (2017). "Bentuk Musik Dan Fungsi Kesenian Jamjaneng Grup Sekar Arum di Desa Panjer Kabupaten Kebumen”. Jurnal: Seni Musik UNNES.

Guerin. 2000. Kritik Dan Sastra. Bandung: Britama Surya.

Indrawan, Andre. (2004). Ilmu analisis musik (IAM) I. Yogyakarta: FSP ISI Yogyakarta.

Jayanti, Amalia Putri. (2016). “Kajian Makna, Nilai Dan Bentuk Lagu Tawar Sedenge Sebagai Lagu Selingan Dalam Upacara Nasional di SMP Negeri 1 Takengon Kabupaten Aceh Tengah". Jurnal: Gondang. UNIMED

Moleong. 2001. Metode Penelitian. Jakarta: Rineka Karya.

Nasution. (1995). Penulisan Karya Ilmiah . Jakarta :Djambatan.

Rohidi, Tjetjep Rohendi. (2014). Metode Penelitian Kualitatif. Bandung: Britama Surya. Sinaga, Bornok. 2018. Pedoman Penulisan Tesis Dan Disertasi Serta Payung Dan Roadmap Penelitian. Unimed Press: Medan

Sugiono. 2016. Metode Penelitian Kuantitatif Dan Kualitatif Dan R\&D. Penerbit Alfabeta: Bandung 
Grenek: Jurnal Seni Musik Vol. 10 No. 1 (Juni 2021) Page: 71-81

Prodi Pendidikan Musik FBS Unimed

p- ISSN 2301-5349

e- ISSN 2579-8200

Sukaria Sinulingga. 2015. Perencanaan dan Pengendalian Produksi. Graha Ilmu. Yogyakarta.

Suroso, Panji. 2018. “Tinjauan Bentuk Dan Fungsi Musik Pada Seni Pertunjukan Ketoprak Dor". Jurnal: GONDANG. Universitas Negeri Medan.

Suroso, Panji. Mukhlis Hasbullah. Ifwatul Hakim. 2019. "Dasar-Dasar Analisis Musik”. Penerbit: CV. Kencana Emas Sejahtera. Medan

Sztompka, Piotr. 2007. Sosiologi perubahan sosial. Jakarta : Prenada

Tumbijo. 2003. Kamus Musik. Yogyakarta: Kanisius. 